\title{
Magic on Wheels: A Study of Re-engagement, Re-enactment and Re- staging the Stereotypes of Performativity and Performance of Persons with Disabilities in the Choreography of Syed Sallauddin Pasha
}

\author{
Radhika Sharma ${ }^{1} \&$ Nagendra Kumar ${ }^{2}$ \\ ${ }^{1}$ Research Scholar, Department of Humanities and Social Sciences, IIT Roorkee. India. E-mail: \\ rsharma@hs.iitr.ac.in, ORCID ID 0000-0001-5163-065X \\ ${ }^{2}$ Professor, Department of Humanities and Social Sciences, IIT Roorkee. India. E-mail: \\ nagendra.kumar@hs.iitr.ac.in
}

\begin{abstract}
Amidst society's segregation of the people among minorities on the basis of gender, race, caste and creed, it is difficult to locate the position of another extreme social minority, i.e. persons with disabilities. But the turn of the century has validated some art and activism performed by persons with disabilities due to which the disabled have marked their position in literature, film and media to some extent, yet they have not secured a position of dignity in the mainstream. To make disabled people visible, Syed Sallauddin Pasha (the father Indian dance therapy for persons with disabilities) initiates his own Natya Shastra i.e. Classical Wheelchair Dances for differently abled artists. Drawing upon Syed Sallauddin Pasha's therapeutic dance choreography, the present paper studies performance arts in the context of differently abled people, and for this, the paper explores the intersection of Performance Studies and Disability Studies. In performing arts (or dance in particular), the body is the medium of representation, likewise, the body defines the identity in the context of disabled people. Therefore, the paper by studying the intersection of Disability Studies and Performance Studies, explores the stereotypes related to the body by scrutinising the disabled dance bodies on the stage. The paper further attempts to explore the idea of accessibility for persons with disabilities by taking into account the assistive devices and accessible architecture. The study then goes into an analysis of spectators' response, stare and gaze towards disability dance performances. In a broader context, the paper offers to scrutinise the negative stereotypes attached to disability and disabled dancing bodies on stage by exploring the nuances in Syed Sallauddin Pasha's choreography.
\end{abstract}

\section{Keywords:}

Performance, disability, dance, physically integrated dance, interdependence, accessibility, gaze

\section{Introduction}

Impairments define the identity of the persons with disabilities and also create meaning for them that is indeed culturally constructed. There is an inadequacy between the somatic identity (i.e. the reality of one's corporeality) and cultural identity (i.e. the selfhood given to one's body by the society and culture) because the body is a docile place where culture carves its social and political 
dogmas. In a culture, it matters whether one is male or female, white or black, rich or poor, able or disable etc., as a result, such binaries of advantage or disadvantage define one's position of privilege in a society. Consequently, the impoverished state of being (i.e. disabled specifically) is considered as an inadequate and inappropriate entity due to which disabled people are ostracised and excluded from the society. Cultural construction of disability marks a disabled body as nonnormative, incapable, distorted, lacking and diminished state of being on the basis of its corporeal impairment. In response to such societal and cultural constructions, Disability Studies scholarship actuates disability as a desirable attribute of difference and thereby rejects its peculiarity as a possible symbol of deficiency.

When a disabled body sneaks into public domains like lanes, streets, hospitals, or in popular culture - it turns into a spectacle for the on-lookers. As a result, a disabled body emerges as a centre of stare and gaze because it startles the spectators due to its bizarre and unruly corporeality. Such reactions, and dictums and scripts that inspire these particular reactions fix the deviant body as an origin of inquisitiveness, disgrace, nuisance, mercy and pity. Carrie Sandahl and Philip Auslander (2005) talk about disability encounter in public space:

[d]isability is a ubiquitous, even mundane, human experience, people with visible impairments almost always seem to "cause a commotion" in public spaces. An encounter with disability elicits surprise, attracting the attention of curious passersby. The curious fight the urge to stare, to gather visual information that will help make sense of such startling physical difference. Disability is considered out of the ordinary, separate from the everyday, a cause for pause and consideration (p. 2).

Therefore, the construction of identity takes place by a course of social performances like the actions of watching, staring, noticing and being noticed. The intrinsic point of disability context is that the lived reality of disability is perpetually performative. Judith Butler (1990) says, "[i]dentity is performatively constituted by the very 'expressions' that are said to be its results." (p. 25). Disability as performative culminates into the idea that there are a series of social performances which constructs identity, and for persons with disabilities, it is the reality of everyday life. Moreover, social sphere acts as an 'inconspicuous theatre' for persons with disabilities where the day to day interaction with disability creates an impression of a set of performances in public. It may be distressing, awkward, shameful, but occasionally, it gives a surprising sense of self and empowerment as a social performer to the person with disabilities that their differences can't be concealed and overshadowed. As Carrie Sandahl and Philip Auslander (2005) observe further:

In daily life, disabled people can be considered performers, and passersby, the audience. Without the distancing effects of a proscenium frame and the actor's distinctness from his or her character, disability becomes one of the most radical forms of performance art "invisible theatre" at its extremes (p. 2).

The stereotyping and stigmatisation of disabled leads to an exclusionary practice simply on the basis of looking in a certain way and the mere presence of disabled creates a situation of disturbance in an ableist world. Boundaries and norms attached to the body create a saying that 'you shouldn't be like this'. As Bree Hadley (2014) says: 
They replay these stereotypes across their own bodies, with different degrees of amplification, exaggeration, counter-position or critical commentary, in the very public spaces and places where this stereotyping typically plays out, or, at least, outside conventional theatrical spaces (p. 14)

In performing arts, performance is the medium of the body and the persons with disabilities are characterised by their corporeality, and therefore, performance offers a chance to the disabled to redefine their bodies. Disability Dance deconstructs the traditional notion of associating dance with able bodies, and therefore, it gives the disable bodies a chance to reformulate themselves. The intersection of Disability Studies and Performance Studies gives disability a theoretical dimension into the field of performing bodies. Carrie Sandahl and Philip Auslander (2005) comment:

At one level, the question of disability is a question of deployment of bodies in space.... At another level, because of their unique cultural and somatic experiences, disabled bodies relate to and define space differently than normative bodies. Performance provides a valuable conceptual model for the consideration of disability because, it, too, is fundamentally about the deployment of body in space...performance studies can be applied a readily to representation of the disabled on stage as to the functioning of disabled bodies in daily life and the ways disabled people choose to represent themselves in both art and social action (p. 9).

This intersection is entangled and intriguing, as it provides a rich ground to explore the superimposing structure of corporeal ability of the body, individuality and cultural conspicuousness, and at the same time it incites the unique paths of scrutinising body, identity, subjectivity and spectatorship. Dance and Disability together help to understand the degree by which one's individuality and subjectivity are connected to one's physicality, and it foregrounds the fact that how childish is the cultural interpretation of disability as bodily incapacity. Contemporary dance, in contrast to the conventional dance, presents a conscious and compassionate dance body that cuts across the boundaries of race, gender, sexuality, bodily ability etc., in order to accept and recognize the profoundness by which these ideologies impact our daily perceptions. In the Introduction of Choreographing Difference (1997), Ann Cooper Albright says, "dance can help us trace the complex negotiations between somatic experience and cultural representationbetween the body and identity" ( $p$. Xiv). Moreover, the cultural connotations attached to disabled people eclipse their talent, performances and aspirations, and look at the disabled performers not fundamentally as performers, but as disabled bodies. Petra Kuppers (2001) remarks:

The disabled performer is marginalised and invisible - relegated to borderlands, far outside the central area of cultural activity, into the discourses of medicine, therapy and victimhood. At the same time, people with physical impairments are also hypervisible, instantly defined in their physicality. The physically impaired performer has therefore to negotiate two areas of cultural meaning: invisibility as an active member in the public sphere, and hypervisibility and instant categorisation. (p. 25)

The present paper aims at exploring the re-engagement, re-enactment and re-envisagement of disabled bodies as performers on the stage in the choreography of Syed Sallauddin Pasha. In 
order to execute an in-depth study, there are two sections in the paper. The first section titled, "A Real Kinaesthetic Empathy: An Endless Unfolding of Human Possibility in Syed Sallauddin Pasha's Therapeutic Dance", studies the wheelchair as an assistive device; an idea of interdependence; and the dance form i.e. Contact Improvisation. The second section i.e. "An Aesthetic Theory of Rasa: Spectators' Response and Gaze towards the Mixed Ability Dancers" discusses the audience response to Syed Sallauddin Pasha's choreography. In a broader scenario, the paper studies the disabled dance body on the stage and the reformulation of some stereotypes attached to a disabled body.

\section{A Real Kinaesthetic Empathy: An Endless Unfolding of Human Possibility in Syed Sallauddin Pasha's Therapeutic Dance}

"I see wheelchair as chariot of Lord Krishna"

(Syed Sallauddin Pasha)

Syed Sallauddin Pasha is the 'Father of Indian Therapeutic Theatre for Persons with Disabilities', popularly known for initiating avant garde dance therapy for people with disabilities in India that promotes equal opportunities, equal platform and inclusion of person with disabilities. Pasha's innovative acts comprise of mythological stories, patriotism, Bollywood songs, society, culture, and so on, represented through classical dance forms enacted on wheelchairs. For this, he established his own "Natya Shastra" and choreographed a number of acts for people with special needs like 'Dance techniques on wheelchairs', 'Yoga on wheelchairs', 'Sufi dance on wheelchairs', 'Bharatanatyam on wheelchairs', 'Bhagwat Gita on wheelchairs', 'Durga on wheelchairs', 'Vande Matram on wheelchairs', 'Bollywood on wheelchairs' and many more. Syed Sallauddin Pasha's initiative i.e. "Miracle on Wheels" and his organisation named "Ability Unlimited Foundation" is ardent towards the cause of Persons with disabilities and envisages itself as the first professional dance theatre for persons with disabilities. Pasha describes the persons with disabilities as "differently abled" people and these differently abled artists improvise themselves as troop of dancers with wheelchairs, and Pasha's choreography provides wings to the wheelchairs of these artists alongside using art as a vehicle to give a message of inclusion to the society. Pasha's dance therapy explores the absolute potential of differently abled artists, because differently abled people do not lack talent, but opportunities and circumstances to seek their talent with which they are lavishly blessed with.

Disability Unlimited Foundation and Syed Sallauddin Pasha's choreography is first of its kind in India that challenges the cultural construction of disability and celebrates the inclusion of disabled artists. Likewise, there are a growing number of such similar dance groups and companies

around the world as well. Ann Cooper Albright (1998) writes about the blooming of disability dance companies:

Each year, the list grows longer as groups such as Mobility Junction (NYC), Danceability (Eugene), Diverse Dance (Vachon Island), Cleveland Ballet Dancing Wheels (Cleveland), Light Motion (Seattle), and Candoco (England) inspire other dance communities to engage with this work. In addition, there are several dance companies such as Liz Lerman's Dancers of the Third Age, which work with older performers, as well as various 
contemporary choreographers who consistently work with nontraditional performers from diverse backgrounds and experiences. (p. 58)

Disability has always been objectified in mainstream art, culture, and media and in response to which Syed Sallauddin Pasha's dance therapy challenges such stereotypical personification of dance, stage and art in relation to disabled body. Taking into consideration Pasha's disability centric art, this section scrutinises the nuances of the(i) Role of Wheelchair in Pasha's Natya Shastra, (ii) Notion of Interdependence and Physically Integrated dance, and (iii) dance form i.e. Contact Improvisation, respectively, in this section.

(i) Role of Wheelchairs in Pasha's Natya Shastra: Wheelchairs are predominant in Pasha's choreography where they don't function as dance props, but as an extension of disabled dancers. This embodiment of partnership between equipment and dancing body invokes a new normal for disabled as it helps to reassess the conceptions of disability. Pasha's creativity and innovation of bringing dance in alliance with Assistive Device (i.e. wheelchair) encourages to re-draft the possibilities of enactment of disability. In Pasha's Therapeutic dance, the role of the wheelchair as an assistive device is not just reformulated but also re-examined through dance, as it turns into a close, communal, physical companion, and a vehicle of mobility and kinetics for disabled dancers. As Merry L. Morris (2015) says, "Explorations in dance with devices, such as wheelchairs, have taken some time to evolve to the current point in which abled/disabled binaries are aggressively broken" (p. 5). Wheelchairs provide wings to the aspirations of disabled dancers an example of which is Pasha's disciple, Gulshan Kumar who registered his name in the Guinness Book of World Record for making sixty-three spins in a single minute. To this Syed Salahudhin Pasha shares his point of view and says, "A wheelchair is more than just a carrier of a body" ("Wheelchair-bound boy creates new Guinness record", 2011).

Materiality of Disabled Dancing Bodies on wheelchairs signifies the fact that such bodies exist, can perform and additionally, wheelchairs harmonize the coordination between disabled and able bodied dancers. Assuming that the disabled dancer's lower body is immobile, then a choreographer can bring into dance only the upper half of a dancer's body by his choreography, and choreograph the movement of the lower body by using assistive device like the wheelchair, stick or cane to create and increase the dynamics of motion. Merry L. Morris says:

[i]n bringing dance in partnership with AT/AD design, there is a re-formulation of how ability and disability enact their possibilities. The device is not only reframed, but

reprioritized through dance in its function. It becomes an intimate, interactive, corporeal partner - a mode of human expression, a means of interaction and support, and a medium of motion and exploration. In these acts, one is prompted to consider the mechanics, form, and materiality of the technology and envision new innovations.

It is crucial in dance to create the ways of innovations in order to alter and modify the potential of the dynamics of motion and spatial dimension. In dance, the concept of mobility is not only confined to the body but also incorporates the accessories like customised shoes, costumes, aerial prowess, chairs, ropes, ladders, and may other equipment of choreographic innovation. On the 
other hand, in the context of people who require an assistive device to compensate for the mobility then such assistive devices function as an extension of the body, and at the same time, it also becomes an important part of choreography. Merry L. Morris (2015) quotes Disability scholar Telory Davies in his paper and says that "dancers with disabilities who use aids create "new versions of the dancing body" as technology assisted bodies (Davies 2008, 48)" (p. 4). Likewise, in Pasha's therapeutic dance, the wheelchair is an integral part of his choreography and it gives a sense of identity and belonging to the differently abled dancers as it blurs the lines between able body and body with special needs.

(ii) The Notion of Interdependence and Physically Integrated Dance: Interdependence is the primary feature of disability aesthetic. Physics of partnering (or pas de deux) plays a crucial role in Physically Integrated Dance, where a non-disabled dancer harbours a differently abled dancer instead of stigmatising the corporeal deviation, e.g. Catherine Cole's Five Feet Feat, a disability dance, theatrical piece, made in partnership with two other non-disabled dancers. Disabled dancers perform the Disability dance, and in contrast to it, the physically integrated dance, incorporates both disabled and non-disabled dancers. Syed Sallauddin Pasha's dance therapy involves the movement potential of mixed ability dancers, i.e. both differently abled and nondisabled dancers. Carrie Sandhal (2018), a Disability theatre scholar, in her paper, says, "[t]he overall choreography of physically integrated dance tends to be inventive within given parameters that are most often established by the way nondisabled people experience the world" (p. 88).

Syed Sallauddin Pasha's choreographed dance performances portray the interdependence between mixed ability dancers where differently abled bodies and non-disabled bodies support each other. Such dance performances that are based on the ideology of alliance and interdependence completely negate and oppose the idea of a self-reliant life that an individualistic society proclaims. Physically Integrated Dance thwarts such independent living goals by bringing together the bodies that are corporeally different from each other on a mutually constructive and same correlative platform. Petra Kuppers (2011) talks about her experience in an integrated and interdependent dance classroom when she says:

In this dance class, we are in a laboratory of disability culture. We are in an environment where many disabled people come together and operate on their own terms, in conversation with non-disabled spaces, ideas, values and concerns that surround us

(p. 2).

The ideology of Interdependence and Physically Integrated dance in Pasha's therapeutic dance also help in occupying the spatial dimension of the stage. Syed Sallauddin Pasha's dancers occupy both horizontal and vertical space on the stage, as differently abled dancers on wheelchairs occupy the horizontal space and non-disabled dancers occupy the vertical space. As Carrie Sandahl (2018) observes:

[t]he dancer who uses the wheelchair, is depicted in three-quarter profile just left of center - a position of prominence that draws focus. The other dancers' bodies emerge at angles away from him, making him the axel of a semi-circular pattern. He occupies a horizontal plane while the dancers with normative legs make use of vertical space by leaping, jumping, and lunging upwards on tiptoe (p. 90). 
Therefore, the idea of interdependence and Physically Integrated dance help in making architectural as well as aesthetic adjustment on the stage which glorifies the idea of kinship and in turn, ultimately signifies the wholeness and completeness of disability aesthetic and art.

(iii) Contact Improvisation: In performing arts, Contact Improvisation is the most kinetic and dynamic dance form founded by Steve Paxton, American experimental dancer and choreographer. In this dance form, there is an exploration of the liaison of one body to another by adopting the basics of contact, motion consciousness and sharing weight. Originally, Contact Improvisation was not envisaged to bring disability into dance but with the passage of time, it has become a predominant dance form adopted by disability dance choreographers. The elements of Contact Improvisation are present in some of the performances of Syed Sallauddin Pasha. Contact Improvisation develops a sort of kinaesthetic empathy amongst the dancers, and both disability dance and physically integrated dance use contact improvisation as a means to accommodate the physical difference which ultimately expands the horizon and interpretation of the standard dance bodies. As Telory Davies (2008) in his article, "Mobility: AXIS Dancers Push the Boundaries of Access", says:

It is primarily the experience of disorientation and sensory re-education in contact that has paved the way for disabled dancers in the larger dance community. Each dancer's body and physical relationship to the space contributes both to contact and to disability dance: difference and accommodation are acknowledged and respected as part of what each dancer brings to the creation process in both these dance forms. (p. 45)

In Syed Sallauddin Pasha's choreography there is a consistent deconstruction and reconstruction of the stereotypical notions about the body. Therefore, his therapeutic dance therapy can be looked at as a revisionist project and an undisguised effort which encourages the advanced manners of looking at differently abled bodies. Moreover, in some of his performances, Contact Improvisation amongst mixed ability dancers gives a sort of affirmation and convention to interact with different corporeal bodies. As there is a restriction of movement because of impairment, contact endows differently abled artists with a sort of advantage to accommodate with an aesthetic built on tactile adjustment. Consequently, Contact Improvisation becomes an experiential art than performing art. Telory Davis (2008) in his article talks about the reframing of new notions about disability dance.

Disabled dancers using canes or wheelchairs as practical extensions of their movement subjectivity prompt audiences to change the conditions of their viewing. In doing so, these contemporary dancers follow both a contact improvisation and a postmodern dance tradition of retraining audience eyes with new movement styles and a new approach to the cultural function of dance (p. 59).

Syed Sallauddin Pasha's creativity and innovation with wheelchair dance, physically integrated dance, and the use of contact improvisation brings disability from the marginalised zones around the periphery of the stage to the middle section of the stage. It makes the audience to think about their presumptions of disability and disabled dancing bodies on stage. Moreover, Pasha's disability dance art is not a victim art or pity seeking art, rather it is adamant towards the breaking 
of the stereotypes about disability as a lacking state of being and hence puts forward the idea that disabled are also humans who can act, perform and dance like non-disabled.

\section{An Aesthetic Theory of Rasa: Spectators' Response and Gaze towards the Mixed Ability Dancers}

Disability Dance and Physically Integrated Dance expects to reinvestigate the act of watching and noticing. The prevalent ways of looking at a disabled body is through the medical gaze and similarly, the dance bodies, in particular, conventionally employ the voyeuristic and scopophiliac gaze. The mixed ability dancers, on the other hand cultivate the advanced ways of looking at themselves and reformulate the aesthetic treatment of gaze on themselves as they try to relocate their marginal status by redefining the conventional stare or gaze upon their bodies. Rosemaire Garland Thomson (1997), a Disability Studies scholar, talks about the visual of disabled bodies as a taboo to able-bodied spectators. "[i]mage of disabled body as a visual assault, a shocking spectacle to the normate eye, captures a defining aspect of disabled experience" (p. 26).

In real life and in the performing arts as well, it is quite hard to point out what persuades spectators and audience reaction to disability. Cultural discourse about disability and spectator's personal identity situation play a crucial role towards the response. Moreover, viewers own proficiency with signs, symbols and nuances of the performing arts solicit the practice of looking, noticing and conceptualising the disabled body on stage, media, court, lane, medical institution and so on. In a culture it matters whether one is male/female, white/black, able/disable, likewise, in performing arts, "the audience may at first recognize a dancer onstage in terms of male or female, black or white, disabled or nondisabled, these visual categories can be disrupted by the kinaesthetic meanings embedded in the dancing itself" ( Albright, 1997, p. Xiv). In other words, the audience's horizontal visual gaze scrutinizes the movement, auditory, corporeal and dimensional impressions of the mixed ability dancers.

The analysis of the audience's response to Syed Sallauddin Pasha's choreographed mixed ability dance performances on various media platform like TV, YouTube, etc., foregrounds the fact that the response is quite positive and altogether different from consuming gaze. The audience is passive while consuming gaze, and the audience buys the ticket then sit, watch and leave the theatre. Contrary to this, Syed Salahudhin Pasha's audience emotionally connects with the dancers, and the implicit contagion of Pasha's dancers' physical motion transmits the incorporeal emotions due to which the viewers look benevolently towards their own muscularity. While examining what modern dance disseminates to its viewers, John Martin, a dance critic underscores a term i.e. "metakinesis". In Introduction to the Dance (1965), John Martin says:

[n]ot only does the dancer employ movement to express his ideas, but, strange as it may seem, the spectator must also employ movement in order to respond to the dancer's intention and understand what he is trying to convey (p. 15).

This response of audience obligation to the dance performance drives a sort of discomfort amongst the viewers. The reason is that Pasha's dancers bring to the light the issues of bodily differences which persuade the audience to look at dancers and their own social and cultural positioning. "In doing so, they prompt spectators-as-performers to replay their own socially assigned role in response" (Hadley, 2014, p. 148). Moreover, Syed Sallauddin Pasha's mixed ability 
dance performances seek to develop a new impact on the audience about the concept of disability. Pasha's choreographed dance performances on online platforms like You Tube, where a channel named "Wheelchair Rockers" and another channel by his name "Syed Sallauddin Pasha" present Pasha's numerous choreographed performances that drive the welcoming and positive response from the viewers in the comment section. Bree Hadley, in his book chapter, "'That you would post such a thing...': Staging Spectatorship Online", talks about the similar sort of online viewership:

Online performances, or offline performances which acquire a mechanism for online responses such as a blog or a 'like' button, provide a unique platform for spectators to perform their response to the disabled body. They provide a unique platform for spectators (bystanders, passers-by, or whatever we might call people passing by on the web) to participate in debates that shape public perceptions of disability, reflect on their own role in perpetuating dominant discourses about disability, and, therefore, reflect on their own role in producing a public sphere that is or is not inclusive of people with disabilities. (Hadley, 2014, p. 110)

In other words, this online viewership and the online response break the fourth wall between the audience and the viewers. In this sort of technological world, mixed ability dance performances, viewers' response to them and viewers' act of spectatorship may start a new phase where spectators may start to re-evaluate and reformulate the cultural scripts and ideologies that marginalise and exclude differently abled people.

\section{Conclusion}

Disability Dance, Mixed Ability Dance, Physically Integrated Dance and Syed Sallauddin Pasha's therapeutic dance foreground the notion that performance can cause a constructive and substantial mediation in the social domain, and also affirm differently abled people to respond to the cultural construction of disability. Moreover, they also provide disabled artists to use their art and performance for creating an impact on the personal and social perceptions of disability. The replay and repetition of the problematic position of the disabled body as 'other' with the performing arts helps persons with disabilities to transform their position in the culture and the society. In fact disability, in mundane scenario, is always a performance that is imitated in the stage performances of disabled artists. The clear binaries of "disabled" and "abled" miss the truth that every individual is temporarily-able bodied (TAB) by one's corporeality and environment in particular. Syed Sallauddin Pasha's dance therapy is not a victim art, rather it helps us to understand the reality of the personality and individuality of differently abled artists, and also brings into our notice that they are no less human as they can act, dance and perform when provided with suitable accessibility and architecture.

\section{Acknowledgement}

We thank Syed Sallauddin Pasha and his initiative i.e. Ability Unlimited Foundation for inspiring and empowering the differently-abled youngsters by recognising, cultivating and channelizing their hidden genius and talent, and consequently transforming their lives.

\section{References}


Albright Cooper, A. (1998). Strategic Abilities: Negotiating the Disabled Body in Dance. Michigan Quarterly Review, XXXVII(3), http://hdl.handle.net/2027/spo.act2080.0037.313

Albright Cooper. A. (1997). Choreographing Difference: the Body and Identity in Contemporary Dance. Wesleyan University Press.

Butler, J. (1990). Gender Trouble: Feminism and the Subversion of Identity. Routledge Publications.

Davies, T. (2008). Mobility: AXIS Dancers Push the Boundaries of Access. Text and Performance Quarterly, 28(1-2), 43-63, https://doi.org/10.1080/10462930701754309

Davis, L. (1995). Enforcing Normalcy: Disability, Deafness, and the Body. London: Verso.

Foucault, M. (1994). The Birth of the Clinic: An Archaeology of Medical Perception. New York: Vintage books.

Garland-Thomson, R. (1997). Extraordinary bodies: Figuring physical disability in American Culture and Literature. New York: Columbia University Press.

Garland-Thomson, R. (1996). Freakery: Cultural Spectacles of the Extraordinary Body. New York: NYU Press.

Goffman, E. (1963). Stigma: Notes on the management of spoiled identity. Englewood Cliffs, N.J: PrenticeHall.

Hadley, B. (2014). Disability, Public Space Performance and Spectatorship: Unconscious Performers. Palgrave Macmillan.

Kuppers, P. (2001). Deconstructing Image: Performing Disability. Contemporary Theatre Review, 11(3-4), 25-40. https://doi.org/10.1080/10486800108568636

Kuppers, P. (2011). Disability Culture and Community Performance: Find a Strange and Twisted Shape. Palgrave Macmillan.

Kuppers, P. (2007). Performing Determinism: Disability Culture Poetry. Text and Performance Quarterly, 27(2), 89-106. https://doi.org/10.1080/10462930701251066

L. Morris, M. (2015). The dance lens: A New Paradigm for Envisioning Assistive Devices and Disability. Theatre and Dance Faculty Publications,

Martin, J. (1968). Introduction to Dance. Journal of Aesthetics and Art Criticism, 26(3), 399-400

Mitchell, D. T., \& Snyder, S. L. (2001). Narrative prosthesis: Disability and the Dependencies of Discourse. Ann Arbor: The University of Michigan Press.

Quayson, A. (2007). Aesthetic Nervousness: Disability and the Crisis of Representation. New York: Columbia University Press. 
11 Magic on Wheels: A Study of Re-engagement, Re-enactment and Re-staging the Stereotypes of Performativity and Performance of Persons with Disabilities in the Choreography of Syed Sallauddin Pasha

Sahu, K, \& Sahu, S. (2015). Attitudinal Barriers Experienced by People with Disabilities. Journal of Disabilities Studies, 1(2)

Sandhal, C. (2018). Disability art and culture: A model for imaginative ways to integrate the community. ALTER: European Journal of Disability Research, 81-95. https://doi.org/10.1016/j.alter.2018.04.004

Sandhal, C., \& Auslander, P. (2005). Bodies in Commotion: Disability and Performance. University of Michigan Press.

The Persons with Disabilities (Equal Opportunities, Protection of Rights and Full Participation) Act (1995). New Delhi: Ministry of Law and Justice, Government of India.

Wheelchair-bound boy creates new Guinness record. (May6, 2011). NDTV. https://www.ndtv.com/delhinews/wheelchair-bound-boy-creates-new-guinness-record-455908

1 Radhika Sharma is a Senior Research Fellow in the Department of Humanities and Social Sciences at Indian Institute of Technology Roorkee, India. Her research concentrates on Disability Studies, Postcolonial Studies, Dalit Studies, Queer Studies, Gender Studies, and Indian Writings in English.

${ }^{2}$ Nagendra Kumar is a Professor of English in the Department of Humanities and Social Sciences at Indian Institute of Technology Roorkee, India. He received Ph.D. from Banaras Hindu University, Varanasi, India. His research areas include South Asian Literature, Dalit Studies, Soft Skills, Indian Writing, Critical Theories, and Technical Communication. 